\title{
Surgery for ulcerative colitis complicated with colorectal cancer: when ileal pouch-anal anastomosis is the right choice
}

\author{
Francesco Tonelli ${ }^{1} \cdot$ Carmela Di Martino $^{1} \cdot$ Andrea Amorosi $^{2} \cdot$ Enrico Mini $^{3} \cdot$ Gabriella Nesi $^{3}$
}

Received: 21 September 2021 / Accepted: 27 January 2022 / Published online: 25 February 2022

(c) The Author(s) 2022

\begin{abstract}
Patients with ulcerative colitis (UC) are at risk of developing a colorectal cancer. The aim of this study was to examine our experience in the treatment of ulcerative Colitis Cancer (CC), the role of the ileal pouch-anal anastomosis (IPAA), and the clinical outcome of the operated patients. Data from 417 patients operated on for ulcerative colitis were reviewed. Fifty-two $(12 \%)$ were found to have carcinoma of the colon $(n=43)$ or the rectum $(n=9)$. The indication to surgery, the histopathological type, the cancer stage, the type of surgery, the oncologic outcome, and the functional result of IPAA were examined. The majority of the patients had a mucinous or signet-ring carcinoma. An advanced stage (III or IV) was present in 28\% of the patients. Early (stage I or II) CC was found in all except one patient submitted to surgery for high-grade dysplasia, low-grade dysplasia, or refractory colitis. Thirty-nine $(75 \%)$ of the 52 patients underwent IPAA, 10 patients were treated with a total abdominal proctocolectomy with terminal ileostomy. IPAA was possible in $6 / 9$ rectal CC. Cumulative survival rate 5 and 10 years after surgery was $61 \%$ and 53\%, respectively. The survival rate was significantly lower for mucinous or signet-ring carcinomas than for other adenocarcinoma. No significant differences of the functional results and quality of life were observed between IPAA patients aged less than or more than 65 years. Failure of the pouch occurred in 5 of 39 $(12.8 \%)$ patients for cancer of the pouch ( $2 \mathrm{pts})$ or for tumoral recurrence at the pelvic or peritoneal level. Early surgery must be considered every time dysplasia is discovered in patients affected by UC. The advanced tumoral stage and the mucous or signet-ring hystotype influence negatively the response to therapy and the survival after surgery. IPAA can be proposed in the majority of the patients with a functional result similar to that of UC patients not affected by CC. Failures of IPAA for peritoneal recurrence or metachronous cancer of the pouch can be observed when CC is advanced, moucinous, localized in the distal rectum, or is associated with primary sclerosing cholangitis.
\end{abstract}

Keywords Ulcerative colitis $\cdot$ Colorectal cancer $\cdot$ Mucinous carcinoma $\cdot$ Signet-ring carcinoma $\cdot$ Ileo-anal-pouch anastomosis $\cdot$ Hyperthermic intraperitoneal chemotherapy

\section{Introduction}

Chronic inflammation of the colorectal mucosa, as is typically found in ulcerative colitis (UC), is an ascertained risk factor for the onset of colorectal cancer (CRC). The development of colorectal neoplasia in patients affected by

Francesco Tonelli

francesco.tonelli@unifi.it

1 Department of Experimental and Clinical Medicine, University of Florence, Florence, Italy

2 Department of Health Sciences, University Magna Graecia of Catanzaro, Catanzaro, Italy

3 Department of Health Sciences, University of Florence, Florence, Italy
UC is related to several factors: duration of UC, extent of colonic involvement, chronically active colitis from childhood, severity of the first attack, primary sclerosing cholangitis (PSC), and family history of CRC [1-4]. Colitis Cancer (CC) is characterized by younger age of occurrence, higher proportion of mucinous and signet-ring cell histology, more proximal colonic distribution, and higher rate of synchronous lesions in confront to sporadic counterpart.

The progression from inflammation to CRC is a multistep process in which the accumulation of genetic mutations leads to sequential mucosal modifications, gradually moving to low-grade dysplasia (LGD), to high-grade dysplasia (HGD), and finally to cancer. Dysplasia can be frequently a multifocal disease. Often, the dysplastic or early neoplastic lesions arising in the colonic mucosa affected 
by UC are not easily found at colonoscopy, because they are flat and not dissimilar from the surrounding inflamed mucosa. However, it is also possible that dysplastic lesions are easily detected as a raised mass (DALM: dysplasiaassociated lesion and mass), showing either the aspect of pedunculated polyp or velvety plaque, similar, respectively, to sporadic adenomatous or villous polyps. Otherwise, thickening and stricturing lesions can be observed especially in long-standing UC. All these alterations are considered precancerous lesions as they result in an increased risk of cancer. Sometimes, these features of the disease are effectively cancerous stigmata. HGDs harbor cancer in more than $30 \%$ of the cases, but also the LGDs can show an infiltrating pattern and a rapid progression in malignancy $[5,6]$.

Given the uncertainties in the detection and classification of UC-associated neoplastic lesions, the surgical indication and the appropriate timing to colectomy particularly in presence of HGD, LGD, or DALM remain controversial. The personal attitude was to operate any case of colitis associated dysplasia. Restorative proctolectomy (RPC) with ileoanal-pouch anastomosis (IPAA) is largely adopted also in $\mathrm{CC}$, but if performing IPAA also in UC complicated by an advanced rectal cancer is a controversial point. Based on an experience of more than 30 years, we report today our results in UC patients affected by $\mathrm{CC}$ and dysplasia.

\section{Patients and methods}

The clinical records of the patients affected by UC observed at the Digestive Surgical Unit of Careggi University Hospital between March 1987 and December 2011 were reviewed. All UC complicated by carcinoma and submitted to surgery have been included in the study. Age at diagnosis, duration, extent, and activity of the disease, preoperative use of immune-modulators and/or biologics, age at surgery, preoperative diagnosis of dysplasia or cancer, localization of CRC, type of surgery, postoperative complications, and adjuvant chemotherapies have been considered.

The site of the CRC was recorded in right, transverse, left colon, and rectum. Extension of disease was valuated according to Montreal classification [7]. CRC was classified according to TNM-UICC 2009 staging system. Nonadenocarcinoma malignancies discovered in the great colon were also recorded. Patients were stratified by pathological stages groups to examine the effect of surgery and complementary therapies on survival. The survival at 5 and 10 years was evaluated.

Local Ethical Committee approved the protocol of the study. Informed consent was obtained from the patients included in the study.

\section{Surgical technique}

Objectives of surgery were to radically remove all the colon and rectum with adequate lymph-node excision and to maintain fecal continence by performing an ileal pouch-anal anastomosis (IPAA). Contraindications to this procedure were the presence of metastatic cancer or locally advanced cancer. In these evidences, proctocolectomy with definitive ileostomy or palliative procedure was chosen. No preoperative radio or chemoradiotherapy was used in patients affected by rectal cancer. Total mesorectal excision was systematically performed when preoperative assessment documented or raised suspicion of rectal cancer.

Different anastomotic techniques were adopted for reconstructive proctocolectomies of our patients. In our first experience, we performed a handsewn IPAA with mucosectomy of the upper canal. This type of IPAA was subsequently reserved to only cases of distal rectal cancer or mucosal dysplasia in proximity of the anal canal. In the last years of our experience, we routinely adopted a double-stapled IPAA. IPAA using a two-stage procedure was adopted in the majority of the patients. In IPAA patients, topic mesalazine was prescribed daily for controlling the inflammation of the residual rectal mucosa sited between the anastomotic line and pectinate line. Endoscopic surveillance of the IPAA patients was performed every year.

Peritonectomy and HIPEC was performed in young patients with $\mathrm{CC}$ associated to diffuse omental and peritoneal carcinomatosis. Mitomycin $\mathrm{C}$ was utilized for intraperitoneal chemotherapy.

\section{Histopathological evaluation}

Multiple sections of all the parts of the surgical specimens were made for the evaluation of the inflammatory disease, its extension in the colon, and the presence of areas of dysplasia or cancer. According to the WHO Classification of Tumors of the Digestive System, carcinoma was defined as mucinous adenocarcinoma or signet-ring cell adenocarcinoma when the proportion of this component was superior to $50 \%$ of the tumor volume.

\section{Functional results}

The functional results of the patients who underwent IPAA were assessed on the answers to a questionnaire over number of defecations, seepage, use of medications, dietary, social, work, and sexual restrictions, satisfaction of the operation. Quality of life was determined by the 
CGQL score [8]. The data obtained were compared with those obtained in IPAA patients without $\mathrm{CC}$ that had been objected of a previous paper [9] and between CC IPAA with age under and over 65 years.

\section{Statistical analysis}

Data were analyzed using SPSS software (SPSS 17.0 for Windows; SPSS, Chicago, IL, USA). The Kaplan-Meier method was used to evaluate the survival. Mean values with standard deviation and Student's $t$ test were used when appropriate; $p<0.05$ was accepted as a significant value.

\section{Results}

From March 1987 to December 2011, 417 patients with UC underwent surgery in our institution. Fifty-two of these patients (12\%) resulted affected by CC. Population characteristics are listed in Table 1. Before surgery, patients have been treated with 5-ASA and steroids, immunosuppressive medications, or biological medications. One of these patients had previously undergone to total colectomy and ileo-rectal anastomosis (IRA) and had developed rectal cancer. There

Table 1 Characteristics of 52 patients with ulcerative colitis cancer

\begin{tabular}{lc}
\hline Characteristics & $\begin{array}{l}\text { Patients } \\
n(\%)\end{array}$ \\
\hline Sex & $19(36.5)$ \\
Female & $33(63.4)$ \\
Male & $11(21.1)$ \\
Smoke & $1(1.9)$ \\
PSC & $30.9(15-65)$ \\
Mean age at diagnosis of ulcerative colitis (yrs, & \\
range) & $53.3(27-77)$ \\
Mean age at diagnosis of CRC (yrs, range) & $16.1(1.1-30.9)$ \\
Duration disease (mean yrs, range) & \\
Extension of disease ${ }^{\mathrm{a}}$ & $35(67.3)$ \\
E3 (Pancolitis) & $16(30.8)$ \\
E2 (left-side colitis) & $1(1.9)$ \\
E1 (Proctitis) & \\
Disease Activity at surgery & $12(23.1)$ \\
Low & $27(51.9)$ \\
Moderate & $13(25)$ \\
Severe & \\
Indications to surgery & $29(55.8)$ \\
CRC & $6(11.5)$ \\
HGD & $11(21.1)$ \\
LGD & $6(11.5)$ \\
Refractory colitis & \\
\hline
\end{tabular}

${ }^{a}$ According to Montreal classification

were 19 (36.5\%) females and 33 (63.4\%) males. Mean age at diagnosis of UC was 30.9 years (range 15-65). Mean age at diagnosis of $\mathrm{CC}$ was 53.3 years (range 27-77). The mean disease duration was 16.1 years (range 1.1-30.9).

The carcinoma arised in cecum, ascending or transverse colon in $23(48 \%)$ patients, in left colon in 18 patients (38.4\%), and in the rectum in another 9 patients (17.3\%). In two patients, a double primary $\mathrm{CC}$ was found. One or more areas of HGD concomitant to CC were detected in 13 patients; meanwhile, areas of LGD were found in another 12 patients. The histopathological data of the $\mathrm{CC}$ are referred in Table 2. The majority of the patients had a mucinous or signet-ring carcinoma. These last types of carcinomas had a significantly different tumoral stage (more stage IV; $p<0.03$, and less stage I; $p<0.02$ ) in confront to the other histological types. Apart from adenocarcinoma, squamous intra-epithelial neoplasia (1 patient) and carcinoid tumors of colon (5 patients) were found at the examination of the surgical specimens. According to TNM-UICC 2009 classification, the stages were the following: Stage $\mathrm{I}=18$ patients (34\%), Stage II $=19(38 \%)$, Stage III $=8(16 \%)$, and Stage IV $=7$ (12\%) (Table 2).

Comparison of the indication to surgery with the pathological stage of the CC is shown in Table 3. Early (stage I or II) CRCs were observed in all except one patients submitted to surgery for HGD, LGD, or intractable or refractory colitis. The only patient of these groups that had an unexpected advanced (stage III) cancer has been operated for LGD discovered at a surveillance colonoscopy. Instead, all the patients submitted to surgery with the diagnosis of

Table 2 Pathological characteristic of the ulcerative colitis cancer

\begin{tabular}{ll}
\hline & $\begin{array}{l}\text { Total } \\
n=52(\%)\end{array}$ \\
\hline Cancer localization & \\
Rectum & $9(17.3)$ \\
Left colon & $20(38.4)$ \\
Transverse & $11(21.1)$ \\
Right colon & $12(23.1)$ \\
TNM-UICC stage & \\
I & $18(34.6)$ \\
II-A & $16(30.8)$ \\
II-B & $3(5.8)$ \\
II-C & 0 \\
III-A & 0 \\
III-B & $4(7.7)$ \\
III-C & $4(7.7)$ \\
IV & $7(13.5)$ \\
Histotype & \\
Mucinous & $27(51.9)$ \\
Signet ring & $4(7.6)$ \\
Adenocarc & $21(40.3)$ \\
\hline
\end{tabular}


Table 3 Pathological stage of Ulcerative Colitis Cancer (TNM-UICC) in relationship to regular endoscopic surveillance and preoperative diagnosis

\begin{tabular}{lccll}
\hline & I & II & III & IV \\
\hline Regular endoscopic surveillance & & & & \\
Yes $n^{\circ} 32$ & $15(47 \%)^{\mathrm{a}}$ & $13(40.6 \%)$ & $1(3.1 \%)$ & $4(12.5 \%)^{\mathrm{a}}$ \\
No $n^{\circ} 20$ & $2(10 \%)$ & $8(40 \%)$ & $7(35 \%)$ & $3(15 \%)$ \\
Preoperative diagnosis & & & & \\
Refractory colitis $n^{\circ} 6$ & $2(33.3 \%)$ & $4(66.7 \%)$ & 0 & 0 \\
Low-grade dysplasia $n^{\circ} 11$ & $8(72.7 \%)$ & $2(18.2 \%)$ & $1(9.1 \%)$ & 0 \\
High-grade dysplasia $n^{\circ} 6$ & $2(33.3 \%)$ & $4(66.7 \%)$ & 0 & 0 \\
Colorectal cancer $n^{\circ} 29$ & $5(17.2 \%)$ & $10(34.5 \%)$ & $7(24.1 \%)$ & $7(24.1 \%)$ \\
\hline
\end{tabular}

a Patients underwent regular endoscopic surveillance had an earlier stage of cancer than those who did not $(p=0.04)$
Table 4 Type of surgery in relationship to the age of the patients and to the stage (TNM-UICC), and site of cancer

\begin{tabular}{llll}
\hline & IPAA & End ileostomy & Palliative surgery \\
\hline $\begin{array}{lll}\text { Age, } n \\
<6537\end{array}$ & $29(78.4 \%)$ & $8(21.6 \%)$ & 0 \\
$>6515$ & $10(66.7 \%)$ & $4(26.7 \%)$ & $1(6.2 \%)$ \\
Site of CRC, $n$ & & & \\
Colon 43 & $34(79.1 \%)$ & $8(18.6 \%)$ & $1(2.3 \%)$ \\
Rectum 9 & $5(55.5 \%)$ & $4(44.4 \%)$ & 0 \\
Stage of CRC, $n$ & & \\
I 18 & $18(100 \%)$ & 0 & 0 \\
II 19 & $14(73.7 \%)$ & $5(26.3 \%)$ & 0 \\
III 8 & $6(75 \%)$ & $2(25 \%)$ & 0 \\
IV 7 & $1(14.3 \%)$ & $5(71.4 \%)$ & $1(14.3 \%)$ \\
\hline
\end{tabular}

CC had confirmed the diagnosis and $48 \%$ of them had an advanced stage (III or IV) CRC. A significative difference of both the rate of advanced CC (stage III and IV) and early CC (stage I and II) was found between patients submitted to regular endoscopic surveillance as compared to those not submitted to surveillance $(p=0.04)$.

Thirty-nine (75\%) of the 52 patients underwent RPC with IPAA, and 10 patients were treated with a total abdominal proctocolectomy with terminal ileostomy. IPAA was indicated in similar rate in patients aged less or more than 65 years. Seven (18\%) patients of 39 IPAA underwent handsewn anastomosis. A stage IV patient with obstructive symptoms underwent palliative surgery consisting in sideto-side ileotransverse anastomosis (Table 4). Pathological features, type of surgery, and follow-up of 9 patients with

Table 5 Characteristics of the ulcerative colitis patients with rectal cancer

\begin{tabular}{|c|c|c|c|c|c|c|c|c|}
\hline Patient & Age at surgery & $\begin{array}{l}\text { Duration of } \\
\text { UC at time of } \\
\text { surgery }\end{array}$ & Type of surgery & Histopathology & TNM & Stage & $\begin{array}{l}\text { Adjuvant } \\
\text { chemo- } \\
\text { therapy }\end{array}$ & Follow-up \\
\hline 1 & 50 & 17 & $\mathrm{TP}+\mathrm{I}$ & MAD & T4N0 & II-B & Yes & Dead after 8 yrs, pulmonary $\mathrm{mtx}$ \\
\hline 2 & 55 & 29 & IPAA & $\mathrm{AD}$ & T2N0 & I & No & Alive at $20 \mathrm{yrs}$ \\
\hline 3 & 66 & 23 & IPAA & MAD & $\mathrm{T} 3 \mathrm{~N} 2$ & III-C & Yes & $\begin{array}{l}\text { After } 3 \text { yrs reoperated for pelvic } \\
\text { recurrence. Dead after } 5 \text { yrs } \\
\text { from IPAA }\end{array}$ \\
\hline 4 & 43 & 19 & IPAA & MAD & T3N0 & II-A & Yes & Alive at $13 \mathrm{yrs}$ \\
\hline 5 & 57 & 18 & IPAA & MAD & T4N1 & III-B & Yes & $\begin{array}{l}\text { After } 3 \text { yrs pouchectomy for } \\
\text { recurrence at IPAA. Dead after } \\
6 \text { yrs from IPAA }\end{array}$ \\
\hline 6 & 36 & 15 & IPAA & $\mathrm{AD}$ & T3N0 & II-A & No & Alive at $17 \mathrm{yrs}$ \\
\hline 7 & 58 & 15 & IPAA & MAD & $\mathrm{T} 3 \mathrm{~N} 2$ & III-C & Yes & $\begin{array}{l}\text { After } 10 \text { months pouchectomy } \\
\text { for pelvic recurrence. Dead } \\
\text { after } 14 \text { months from IPAA }\end{array}$ \\
\hline 8 & 42 & 6 & $\mathrm{TP}+\mathrm{I}$ & Signet ring & T4N2M1 & IV & Yes & Dead after 2 yrs \\
\hline 9 & 56 & 15 & $\mathrm{TP}+\mathrm{I}$ & Signet ring & T3N2M1 & IV & Yes & Dead after 10 months \\
\hline
\end{tabular}

$H G D$ High-grade dysplasia, $A D$ Adenocarcinoma, $M A D$ Mucinous adenocarcinoma, IPAA Ileo pouch-anal anastomosis, $T P+I$ Total proctocolectomy and terminal ileostomy 
$\mathrm{CC}$ at the rectum are indicated in Table 5. In all but one of these patients, the rectal cancer was locally advanced (T3 or 4) or metastatic. Only 4 patients had a prolonged survival; meanwhile, the other 5 had a pelvic recurrence or a metastatic disease. All these patients were affected by a mucinous or signet-ring cancer. Four patients underwent peritonectomy (two with associated HIPEC) for peritoneal metastasis from mucinous carcinoma ( 3 patients) or signet-ring carcinoma (1 patient) discovered at time of colectomy or arised 10-15 months after IPAA. The score of peritoneal cancer index changed between 11 and 25. Median overall survival of the patients submitted to peritonectomy was 29 months with 3 years survival of $25 \%$.

No operative death was observed. Global survival rate of our case series was 122 months as a median, with a 5 and 10 year survival rate of $61 \%$ and $53 \%$, respectively. Cumulative survival rate for all the patients and that for the subgroups of patients divided on the base of the pathological stage are shown in Figs. 1 and 2. The cause of death was progression of cancer for a local and/or peritoneal recurrence or for distant metastases. The survival rate at 5 and 10 years from surgery was significantly lower $(p>0.01)$ in patients with mucinous or signet-ring carcinomas than in patients with non-mucinous adenocarcinoma ( $43 \%$ vs $75 \%$ at 5 years and $39 \%$ vs $70 \%$ at 10 years). Two patients developed a metachronous cancer at the level of IPAA. One of them was affected by PSC and showed an advanced cancer inside the pouch 52 months after stapled IPAA. The other patient had a recurrence at the anal transitional zone (ATZ) after a stapled IPAA. The treatment and follow-up of these patients and of other 3 patients who manifested a failure of IPAA due to the local recurrence of the cancer are indicated in Table 6. The removal of the pouch was performed in 5 of $38(13.1 \%)$ patients, more often than in UC patients submitted to IPAA for other indications [7 of 333 IPAA $(2.1 \%) p=0.001$ ]. The IPAA failure (excision of the pouch or maintenance of diversion) was observed globally in 5 of 39 patients $(12.8 \%)$ and in 3 of the 6 patients (50\%) submitted to IPAA for a rectal cancer. The cause of the pouch failure was IPAA cancer (2 patients) or tumoral peritoneal or pelvic recurrence (3 patients). In all but one of these patients, the cancer pattern was mucinous. Mean duration of the pouch in the patients in whom failure occurred was 15 (range 10-52) months.

An unusual tumoral manifestation was observed in a 31 year old male who was submitted to a stapled IPAA for a mucinous cancer (T2N1) of transverse colon associated with multiple area of HGD in the colon. Area of LGD was present also in the rectum. The pathological examen of the surgical specimen showed a squamous intra-epithelial lesion with a diameter of $0.25 \mathrm{~cm}$ surrounded by anal transitional mucosa at the distal margin of the surgical resection. In the following months, biopsies of the mucosa of the anal canal showed dysplastic growth of squamous epithelial in the ATZ. Therefore, 10 months after the first operation, a mucosectomy of the ATZ and a redo-IPAA was performed. The patient maintained a normal function of the pouch in the following years without recurrence of dysplasia or cancer. Considering only the IPAA patients without recurrence of cancer, the functional result and the quality of life evaluated at least 1 year after surgery were not different from those of
Fig. 1 Cumulative Stage $\mathrm{I}=0$, Stage II-A $=1$, Stage II-B $=2$, Stage III $=3$, and Stage $\mathrm{IV}=4$

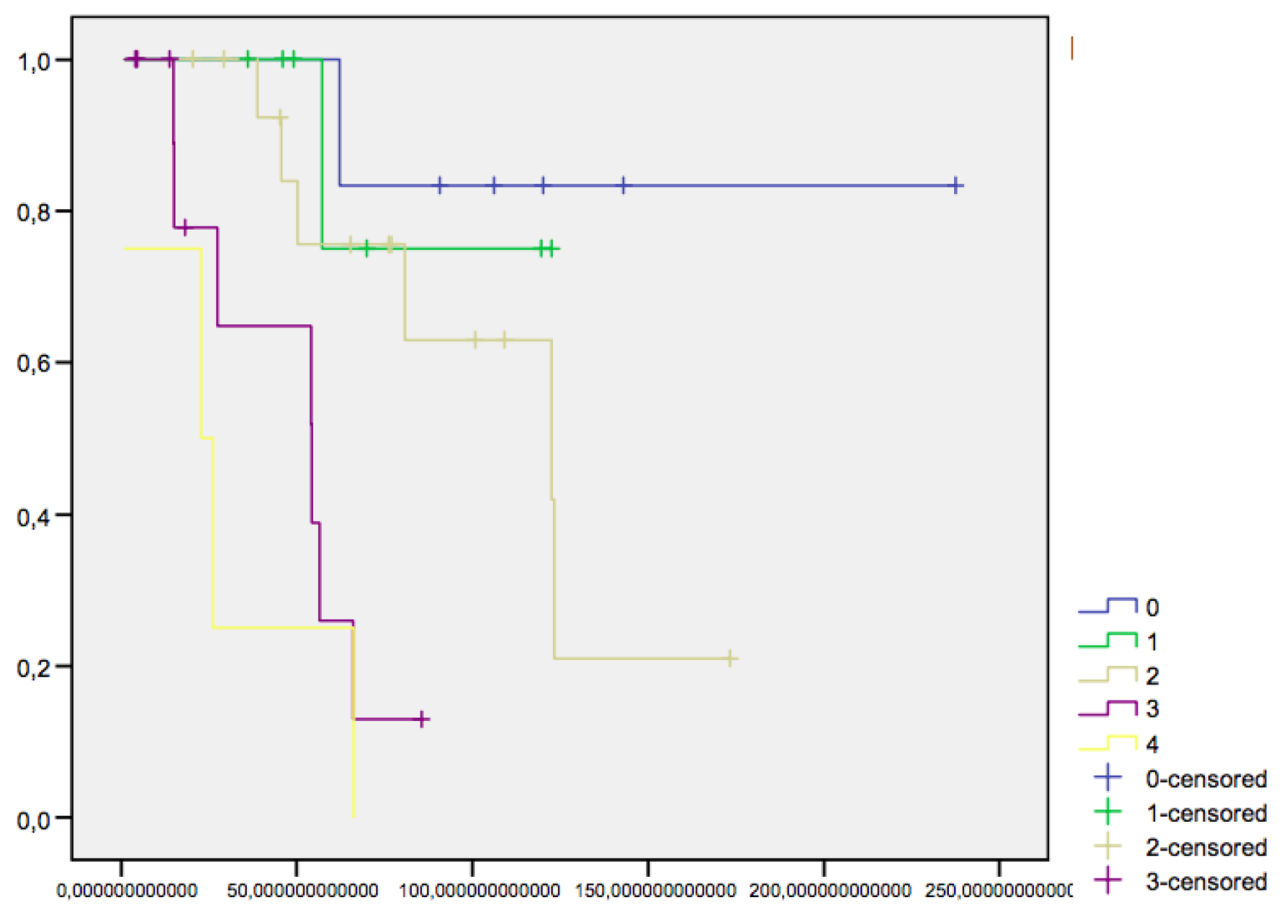


Table 6 Causes of pouch failure in 5/39 IPAA for ulcerative colitis cancer

\begin{tabular}{|c|c|c|c|c|c|c|c|c|}
\hline $\begin{array}{l}\text { Patient } \\
\text { sex/age } \\
(y r s)\end{array}$ & $\begin{array}{l}\text { Cancer locali- } \\
\text { zation }\end{array}$ & Histotype & Stage & Type of IPAA & $\begin{array}{l}\text { Time from } \\
\text { IPAA }\end{array}$ & $\begin{array}{l}\text { Causes of } \\
\text { failure }\end{array}$ & Treatment & Follow-up \\
\hline$F / 31$ & Transverse & Mucinous & II (T3N0) & Stapled & $52 \mathrm{~m}$ & $\begin{array}{l}\text { Pouch cancer } \\
\text { T4N2M1 }\end{array}$ & Pouch excision & Death 8 months \\
\hline $\mathrm{M} / 43$ & Cecum & Mucinous & II (T3N0) & Stapled & $17 \mathrm{~m}$ & $\begin{array}{l}\text { Peritoneal } \\
\text { Carcinosis }\end{array}$ & Ileostomy & Death 2 months \\
\hline M/66 & Distal rectum & Mucinous & III (T3N2) & Handsewn & $26 \mathrm{~m}$ & $\begin{array}{l}\text { Pelvic recur- } \\
\text { rence }\end{array}$ & Pelvectomy & $27 \mathrm{~m}$ \\
\hline $\mathrm{F} / 57$ & $\begin{array}{c}\text { Proximal } \\
\text { rectum }\end{array}$ & $\begin{array}{l}\text { Adenocarci- } \\
\text { noma with } \\
\text { colloid com- } \\
\text { ponents }\end{array}$ & III (T4N1) & Stapled & $38 \mathrm{~m}$ & $\begin{array}{l}\text { Cancer at anas- } \\
\text { tomotic line } \\
\text { T3N0 }\end{array}$ & Pouch excision & Death 3 yrs \\
\hline $\mathrm{M} / 35$ & Distal rectum & Mucinous & III (T3N2) & Stapled & $10 \mathrm{~m}$ & $\begin{array}{l}\text { Pelvic-perito- } \\
\text { neal recur- } \\
\text { rence }\end{array}$ & Pouch excision & $4 \mathrm{~m}$ \\
\hline
\end{tabular}

IPAA operated without CC. No significant differences of the functional results and quality of life were observed between IPAA patients aged less than or more than 65 years. Patients under 65 had diurnal bowel movements of 4.5 (mean, SD 2.4) and nocturnal bowel movements of 0.9 (mean, SD 0.4); meanwhile, patients over 65 had diurnal bowel movements of 4.2 (mean, SD 1.5) and nocturnal bowel movements of 1.3 (mean, SD 0.3). No difference was recorded between these two groups for daily or nightly seepage. The ability to distinguish flatus from stool was present in the $95 \%$ of under 65 and in $90 \%$ of over 65 IPAA patients. All patients were satisfied with surgery and would recommend it. Work, social, sexual, and dietary restrictions were similar between the two groups. The mean CGQL score was 0.75 (SD 0.11) in under 65 and 0.73 (SD 0.14) in over 65 ( $p=$ n.s.). The patients with handsewn anastomosis had a less-satisfying functional result with imperfect continence in $28 \%$ of them, due to nocturnal seepage and/or urgency to defecate.

\section{Discussion}

We observed CC in our UC surgical series in 52 of the 417 operated patients, equivalent to $12.5 \%$. The incidence of $\mathrm{CC}$ in the published UC case series is extremely variable from $1.4 \%$ to $34 \%$ [4]. This so large difference depends by several variables. The factors that weigh most in the event of CC are the duration of the UC and the extent of mucosal inflammation. Analyzing 6 studies that have considered only the pancolitis, the cumulative CRC risk is $2.1 \%, 8.5 \%$, and $17.8 \%$, respectively, at 10, 20, and 30 years from the diagnosis [4]. The higher incidence of $\mathrm{CC}$ is found in gastroenterological, surgical, or tertiary referral centers that make an important selection of the patients. This is also the reason of the rather high incidence of $\mathrm{CC}$ in our case series. In the last time, surveillance protocol, endoscopic treatment of dysplasia, timely colectomy, and medical treatment inducing remission of the inflammatory activity have been used more than in the past and had determined less CC [10-12]. A more precise and real estimate of the $\mathrm{CC}$ incidence comes from the data of the national cancer registries. For example, the cumulative incidence of CC in the population-based Swedish Registry at 10,20 , and 30 years after diagnosis of IBD is $1 \%, 1.5 \%$, and $2.7 \%$, respectively [13]. Furthermore, the most recent studies consider for an appropriate evaluation of the CC risk the standardized incidence ratio (SIR) which compares the observed number of CCs to the expected number of CRCs in general population [14]. However, the risk of CC remains very high in UC patients with concurrent PSC. CC develop in $14 \%$ and $31 \%$ of these patients 10 years and 20 years from the beginning of the disease, respectively [15].

The mean age at diagnosis of $\mathrm{CC}$ in our experience was 53.3 yrs similar to that observed in other experiences and significantly earlier than mean age at diagnosis of sporadic CRC [16-19]. Like in other experiences, we had showed an increased proportion of CCs in males in confront of the females. This phenomenon reflects the same protective effect of estrogens invoked for explain the lower incidence of adenomatous polyps and CRC in premenopausal women or in women who had used hormone replacement therapy. The effects of estrogens are mediated by the cellular presence of estrogen receptors (ER) [20, 21].

More the $40 \%$ of the CC in our series was located in the right colon. Also, other authors report a similar distribution of CC in UC patients [15, 22-26], but several other authors found more often the carcinoma in the left colon or in the rectum than in right colon [14, 16, 24-26]. This difference could be related to the extension of the colitis: all our CCs found proximally of the splenic flexure were arised in UC pancolitis. An early stage CC was 
predominant in our case series $(>70 \%)$. These data are different from that observed in the sporadic CRC and in some CC series in which almost $50 \%$ of CCs were stage I and II and other 50\% stage III and IV [17, 19, 27-29], but similar to other authors. They have noticed less-severe tumor stages of the discovered $\mathrm{CC}$ in the last 2 decades in confront to the past $[2,11,16,26,30]$. These data could depend from increased awareness of the neoplastic risk and a more extensive, and accurate surveillance programs with a good compliance of the patients in the last years in confront of the past. In our experience, the survival of CC patients is $61 \%$ and $53 \%$ at 5 and 10 years of follow-up, respectively. It is controversial if CC survival is equal, worst, or better in confront of sporadic CRC. The survival of CC is first of all related to the stage at which CC is diagnosed and treated. In many case series, the survival is similar to that of sporadic CRC $[22,24,26,31,32,34$, $35]$, but in other experiences, it is worse [17, 27, 33, 36] even if a lower rate of advanced stages of $\mathrm{CC}$ was observed due to the program of surveillance protocol [37]. In particular, it has been observed that stages III CC had a worse prognosis in confront of sporadic CRC [14, 33], and metastatic CC patients have shorter survival and less benefit from standard chemotherapy than metastatic sporadic CRC patients [38]. The reason of this bad prognosis could be related to the pathological features of $\mathrm{CC}$, different from that of the sporadic CRC, and to the high rate of mucinous and signet-ring cell adenocarcinoma present in CC. Mucinous and signet-ring cell histotypes are rare in sporadic CRC with an incidence, respectively, of 10-20\% and $0.9-4 \%$, but are found frequently in our as in other case series and could be responsible of a higher rate of lymphnodal and peritoneal diffusion and a poorer responsiveness to chemotherapic or radiotherapic regimens [24, 39]. The molecular carcinogenetic process of UC deeply different from that of adenoma-carcinoma sequence usually observed in sporadic CRC can explain this phenomenon. Early events of CC are represented by DNA methylation that induces inhibition of oncosuppressor genes and $M M R$ gene (MMR) promoter regions, mutation of $p 53$, aneuploidy, and microsatellite instability (MSI). MSI-high (H) was found approximately in more than $30 \%$ of UC-associated carcinomas or HGDs [40]. MSI-H/deficient MMR is considered a favorable prognostic factor for nonmetastatic colon adenocarcinoma, but did not show survival advantage in the advanced CRC and is not accompanied to better survival in patients treated with 5-fluorouracil-based adjuvant chemotherapy [41, 42].

To improve patient prognosis, we performed cytoreductive peritonectomies hoping to have a better response to chemotherapy. There is a limited experience of peritonectomy and in particular of HIPEC in the setting of CC. Our experience was rather disappointing, but can be proposed for preventing intestinal obstruction and in young patients.

The discovery of dysplasia at biopsies during a colonoscopy for the surveillance program asks the question if immediate surgery is justified. Meanwhile, the diagnosis of HGD makes easy the decision of operation, because the presence of CC is very high, varying from 42 to $67 \%$ [43, 44], and the management of UC with LGD remains a difficult decision. Some centers in which the progression of LGD to advanced lesions (HGD or CRC) or the association with an unrecognized CRC was found extremely high [45, 46], even up to $50 \%$ and $20 \%$, respectively, have advocated prompt surgery. Other centers have observed few or no progression of LGD to advanced neoplasia following the patients for many months [47, 48]. A recent metanalysis has been focused on the risk factors for the progression of LGD to CRC. They are LGD in the distal colon, long-standing UC, flat or invisible lesion, diagnosis of dysplasia from an expert gastrointestinal pathologist [48]. Instead, a raised morphology of LGD does not represent a risk factor as these lesions can be more easily discovered, totally resected, and simply controlled at followup [49]. Since the estimation of the progression of LGD to an advanced neoplasia is variable in studies published so far, the management of LGD in UC patients remains controversial to date. A randomized prospective multicenter study comparing continuing surveillance vs colectomy at LGD diagnosis with CRC-related death, quality of life, and death from all causes, as primary outcome measures, would be auspicable to resolve this debate, but has not been performed either because a similar study could be criticized for ethical reasons but also for practical difficulties due to validate the best method of identification and characterization of LGD [50, 51]. Until prospective studies on LGD and UC patients will better clarify the real progression of LGD, the indication to surgery should be remain a valid option and its cost-benefit should be showed and discussed with the patients. This direction is confirmed by a recent consensus of ECCO [52].

Given the multiplicity and the possible recurrence of neoplastic lesions, it is inappropriate to adopt partial colonic resections for $\mathrm{CC}$ patients, as in the past has been proposed particularly for elderly patients [53, 54]. Even subtotal colectomy with IRA is criticizable, since the presence of colonic carcinoma or dysplasia at time of surgery is an important risk factor for the evidence of cancer in the rectal stump [55]. Therefore, proctocolectomy should be the right choice for $\mathrm{CC}$, but it remains to clarify if is better to do a definitive end ileostomy or to perform RPC. In the last decades, the widely accepted surgical procedure for UC patients requiring surgery has been RPC with IPAA. This procedure was largely adopted also in UC complicated by dysplasia or cancer. The result of IPAA is satisfactory with a good function not different from that achieved for IPAA performed in the absence of 
$\mathrm{CC}[32,56]$. We can confirm the good function of the pouch even when the operation was performed in patients more than 65 years old. After all it has been demonstrated that IPAA does not adversely affect quality of life in old patients although daytime and nighttime incontinence is more common than in young patients [57]. However, the failure rate of the pouch performed in UC patients affected by CC can be high varying between $14.2 \%$ and $19 \%$ [39, 56, 58, 59] and most of the time significantly higher than that observed in IPAA with the absence of CRC. Our experience of pouch failure $(12.8 \%)$ confirms what other authors have observed. The only exception is the case series of Al-Sukni et al. [32] that have found only a $6 \%$ of failure not dissimilar from the failure observed in their experience for IPAA without CC. This good result could be due to the low number of advanced rectal cancer observed and treated with IPAA in their experience. Moreover, how often IPAA is performed when CC is sited in the rectum is not clear, because these data are not indicated in the majority of the published experiences. For example, the most common operation performed at the Mayo Clinic was total proctocolectomy with end ileostomy which was utilized in $51 \%$ of the 41 UC patients with rectal adenocarcinoma; meanwhile, IPAA was performed in only $27 \%$ of them [60]. In our experience, IPAA was adopted in $66 \%$ of the $\mathrm{CC}$ sited in the rectum. Seeing the results published in the literature and our personal experience, IPAA performed in the presence of rectal cancer is successful when the tumor stage is favorable with a low rate of failures, whereas IPAA performed for a locally advanced cancer is accompanied by a high rate of failures between $16.5 \%$ and $28.5 \%$ [58, 60, 61]. The advanced stage of the rectal cancer favors a local recurrence especially if the cancer arises in the rectal middle or lower third. To prevent tumoral recurrence, it would be taken in consideration either pre-operatively or post-operatively a pelvic radiotherapy. Looking to sporadic rectal cancers, preoperative radiotherapy or radiochemotherapy is usually indicated for downstaging T3-4 or $\mathrm{N}+$ tumors of the middle and lower rectum. However, this treatment was rarely chosen for rectal cancers arised in UC. Preoperative radiotherapy was chosen in only 11 patients ( 9 by Wu et al. [39], 1 by Zmora et al. [59], 1 by Gorfine et al. [56]). High rate of severe complications (chronic pouchitis, local sepsis) was observed with the result of pouch failure in 5/11 patients (45\%). Even more devastating can be the consequences of the postoperative radiotherapy which inevitably provokes radiation damage to the pouch and the enteric loops dislocated in the pelvis. All seven patients with IPAA who had postoperative radiotherapy had a pouch failure (1 by Remzi et al. [61], 1 by Zmora et al. [59], 3 by Wu et al. [39], 1 by Gorfine et al. [56], 1 by Merchea et al. [60]). We have not adopted radiotherapy neither pre-, nor post-operatively for the fear of exacerbation of the inflammatory disease. The European evidence-based consensus had recommended that radiotherapy should be avoided after IPAA [52]. Conversely, in locally advanced cases, it could be useful to perform radio or radiochemotherapy pre-operatively, and then choosing total proctocolectomy with end ileostomy, since the risk of pouch failure is possible in one of two patients. However, it remains to establish if radiotherapy is able to reduce the local recurrence in advanced rectal tumors arising in UC. Mucinous rectal adenocarcinoma shows a reduced rate of downstaging, an increased rate of positive margin, and poorer overall survival in confront to non-mucinous rectal adenocarcinomas following preoperative chemoradiotherapy [62]. We have frequently found this histopathological type in CCs arising in the rectum and have observed that all the recurrent rectal tumor after total proctocolectomy had a mucinous pattern. The same histotype was considered as a risk factor for the demolition of the pouch in other surgical experience [39].

Another point to be debated is whether performing IPAA for $\mathrm{CC}$ could expose to the development of dysplasia or cancer in the pouch. Both the ileal pouch mucosa, that with time undergoes to metaplasia and chronic inflammation, and the residual rectal mucosa below the ileo-anal anastomosis are at risk of developing dysplasia and/or carcinoma. An accurate revision of the IPAA cancers referred in the literature was made by Das et al. in 2007 [63]. They found only 17 authentic (i.e., not due to local recurrence of the treated CC or to progression to cancer of the dysplasia that persists at the level of ileo-anal anastomosis) adenocarcinoma in the pouch or in the anorectal mucosa. The majority of these carcinomas are arising from residual rectal mucosa at the level of ATZ. The time intervals from RPCT to the diagnosis of cancer are usually longer than 2 years. The occurrence of pouch cancer following IPAA is very rare. Only two pouch cancers were found by Mark-Christensen et al. [64] over a total of 1723 patients operated for ulcerative colitis at a median follow-up of 12.9 years.

PSC could be another risk factor for pouch cancer onset. UC patients with PSC are at increased risk of CRC either in the intact colon or in the rectal stump after subtotal colectomy and IRA, but the neoplastic risk after RPC has not well defined even if seems a probable event. Imam et al. had followed 65 patients operated on with IPAA for refractory colitis (40\%), dysplasia (48\%), or carcinoma (10.8\%). [65]. The cumulative 5-year incidence of pouch neoplasia was $5.6 \%$. We have observed an advanced cancer of the pouch 4 years after RPC in a PSC-UC patient in whom CC had grown up in transverse colon.

Another point to debate is if the type of pouch anastomosis (i.e., handsewn at the level of pectinate line after mucosectomy of the rectal mucosa of the anal canal, or stapled at the level of the distal rectal mucosa) affects the onset of cancer in ATZ. Several authors have found similar onset of dysplasia or cancer for both anastomotic 
techniques $[32,66]$. No cases of ATZ adenocarcinoma, but only presence of ATZ dysplasia was found in $2.9 \%$ and in $3.9 \%$ of the 532 stapled IPAA at 10 and 15 years of follow-up, respectively [69]. The discovery of ATZ dysplasia was significantly associated to pathological findings of dysplasia or cancer in the colectomy specimen. Dysplasia of ATZ was managed by mucosectomy or simply controlled depending on the number of positive biopsies and the degree of dysplasia [67]. However, most of the time, ATZ dysplasia and cancer can derive from dysplasia, which was already present in the rectal mucosa when IPAA was performed [63]. Therefore, mucosectomy is recommended when dysplasia or cancer had developed in the distal rectum and intensive endoscopic surveillance with multiple biopsies of ATZ must be taken into account if mucosectomy was not performed in similar cases [68].

Recently, some cases of squamous cell carcinoma (SCC) after IPAA have been showed [69]. The majority of these cancers (five cases) are found in the ATZ zone or in the rectal cuff, but two cases are described in the pouch. These tumors seem to onset by the squamous metaplasia of the rectal or ileal mucosa. The treatment of SCC is referred only in three of the seven published cases and had consisted in chemoradiotherapy. Obviously, this treatment can compromise the function of the pouch, but can be cure the SCC that is extremely sensitive to chemoradiotherapy. We discovered an incidental squamous intra-epithelial neoplasia at the pathological examen of the surgical specimen. This premalignant lesion can progress to invasive carcinoma in HIV positive or in immunocompromised patients. Surgical excision of the anal transitional zone maintaining a functional pouch can avoid the recurrence of the lesion, how it happened in the case we have observed.

\section{Conclusions}

Early surgery must be considered when dysplasia is discovered in patients affected by UC. Long-standing colitis, pancolitis, and sex male favor the development of CC. At least $40 \%$ of CC is diagnosed at an advanced tumoral stage and are mucous or signet-ring carcinoma. These factors influence negatively the tumor stage, the response to complementary therapy, and the survival after surgery. IPAA can be proposed in the majority of the patients with a result similar to that of UC patients not affected by CC. Failures of IPAA for peritoneal recurrence or metachronous cancer of the pouch can be observed when CC is advanced, is localized in the distal rectum, or is associated with PSC.

\section{Declarations}

Conflict of interest The authors declare that they have no conflict of interest.

Research involving human participants All procedures performed in the study were in accordance with the ethical standards of the institutional and national research committee and with the 1964 Helsinki declaration and its later amendments or comparable ethical standards.

Informed consent Informed consent was obtained for the surgical procedure prior to their participation.

Open Access This article is licensed under a Creative Commons Attribution 4.0 International License, which permits use, sharing, adaptation, distribution and reproduction in any medium or format, as long as you give appropriate credit to the original author(s) and the source, provide a link to the Creative Commons licence, and indicate if changes were made. The images or other third party material in this article are included in the article's Creative Commons licence, unless indicated otherwise in a credit line to the material. If material is not included in the article's Creative Commons licence and your intended use is not permitted by statutory regulation or exceeds the permitted use, you will need to obtain permission directly from the copyright holder. To view a copy of this licence, visit http://creativecommons.org/licenses/by/4.0/.

\section{References}

1. Bergeron V, Vienne A, Sokol H, Seskiuk P, Nion-Larmurier I, Ruskone-Fourmestraux A, Svreck M, Beaugerie L, Cosnes J (2010) Risk factors for neoplasia in inflammatory bowel disease patients with pancolitis. Am J Gastroenterol 105:2405-2411

2. Olén O, Askling J, Sachs MC et al (2017) Childhood onset inflammatory bowel disease and risk of cancer: a Swedish nationwide cohort study 1964-2014. BMJ 358:j3951

3. Askling J, Dickman PW, Karlén P et al (2001) Family history as a risk factor for colorectal cancer in inflammatory7 bowel disease. Gastroenterology 120:1356-1362

4. Eaden JA, Abrams KR, Mayberry JF (2001) The risk of colorectal cancer in ulcerative colitis: a meta-analysis. Gut 48:526-535

5. Thomas T, Abrams KA, Robinson RJ et al (2007) Meta-analysis: cancer risk of low-grade dysplasia in chronic ulcerative colitis. Aliment Pharmacol Ther 25:657-668

6. Ullman TA (2003) Patients with low grade dysplasia should be advised to undergo colectomy. Inflamm Bowel Dis 9:267-269

7. Silverberg MS, Satsangiu J, Ahmad T et al (2005) Toward an integrated clinical, molecular and serological classification of inflammatory bowel disease: report of a working party of the 2005 Montreal World Congress of Gastroenterology. Can J Gastroenterol 19(Suppl A):5-36

8. Scarpa M, Ruffolo C, Polese L et al (2007) Quality of life after restorative proctocolectomy for ulcerative colitis. Arch Surg 142:158-165

9. Tonelli F, Di Martino C, Giudici F (2016) Could total colectomy with ileorectal anastomosis be an alternative to total proctocolectomy with ileal pouch-anal anastomosis in selected ulcerative colitis patients? Gatsroenterol Res Pract 2016:5832743

10. Jess T, Rungoe C (2012) Peyrin-Biroulet Risk of colorectal cancer in patients with ulcerative colitis: a meta-analysis of populationbased cohort studies. Clin Gastroenterol Hepatol 10:639-645 
11. Castano-Milla C, Chaparro M, Gisbert JP (2014) Systematic review with meta-analysis: the declining risk of colorectal cancer in ulcerative colitis. Aliment Pharmacol Ther 39:645-649

12. Choi PM, Nugent FW, Schoetz DJ, Silverman ML, Haggitt RC (1993) Colonoscopic surveillance reduces mortality from colorectal cancer in ulcerative colitis. Gastroenterology 105:418-424

13. Soderlund S, Brandt L, Lapidus A, Karlén P, Bostrom O, Lofberg R, Ekbom A, Askling J (2009) Decreasing time-trends of colorectal cancer in a large cohort of patients with inflammatory bowel disease. Gastroenterology 136:1561-2157

14. Kappelman MD, Farkas DK, Long MD, Erichsen R, Sandler RS, Sorensen H, Baron JA (2014) Risk of cancer in patients with inflammatory bowel disease: a nationwide population-based cohort study with 30 years of followq-up. Clin Gastroenterol Hepatol 12:265-273

15. Claessen MMH, Vleggar FP, Tytgat KMAJ et al (2008) High lifetime risk of cancer in primary sclerosing cholangitis. J Hepatol 50:158-164

16. Connel WR, Talbot IC, Harpaz N, Britto N, Wilkinson KH, Kamm MA, Lennard-Jones JE (1994) Clinicopathological characteristics of colorectal carcinoma complicating ulcerative colitis. Gut 35:1419-1423

17. Watanabe T, Konishi T, Kishimoto J et al (2011) Ulcerative colitis-associated colorectal cancer shows a poorer survival than sporadic colorectal cancer: a nationwide Japanese study. Inflamm Bowel Dis 17:802-808

18. Averboukh F, Ziv Y, Kariv Y, Zmora O, Dotan I, Klausner JM, Rabau M, Tulchinsky H (2011) Colorectal carcinoma in inflammatory bowel disease: a comparison between Crohn's and ulcerative colitis. Colorectal Dis 13:1230-1235

19. Kavanagh DO, Carter MC, Keegan D, Doherty G, Smith MJ, Hyland JM, Mulcahy H, Sheahan K, O'Connel PR, O'Donoghue DP, Winter DC (2014) Management ofcolorectal cancer in patients with inflammatory bowel disease. Tech Coloproctol 18:23-28

20. Williams C, Di Leo A, Niv Y, Gustafsson J (2016) Estrogen receptor beta as target for colorectal cancer prevention. Cancer Lett 372:48-56

21. Principi M, Barone M, Pricci M, De Tullio N, Losurdo G, Ierardi E, De Leo A (2014) Ulcerative colitis: from inflammation to cancer. Do estrogen receptors have a role? World J Gastroenterol 20:11496-11504

22. Ohman U (1982) Colorectal carcinoma in patients with ulcerative colitis. Am J Surg 144:344-349

23. Hughes RG, Hall TJ, Block GE et al (1978) The prognosis of carcinoma of the colon and rectum complicating ulcerative colitis. Surg Gynecol Obstet 146:46-48

24. Delaunoit T, Limburg PJ, Goldberg RM, Lymp JF, Loftus EV Jr (2016) Colorectal cancer prognosis among patients with inflammatory bowel disease. Clin Gastroenterol Hepatol 4:335-342

25. Aarnio M, Mustonen H, Mecklin JP, Jarvinen HJ (1998) Prognosis of colorectal cancer varies in different high-risk conditions. Ann Med 30:75-80

26. Shaukat A, Salfiti NI, Virnig DJ, Howard DH, Sitaraman SV, Liff JM, Lederle FA (2012) Is ulcerative colitis associated with survival among older persons with colorectal cancer in the US? A population-based case-control study. Dig Dis Sci 57:1647-1651

27. Herrinton LJ, Liu L, Levin TR, Allison JE, Lewis JD, Velayos F (2012) Incidence and mortality of colorectal adenocarcinoma in persons with inflammatory bowel disease from 1998 to 2010 . Gastroenterology 143:382-389

28. Lutgens MW, Vleggaar FP, Schipper ME et al (2008) High frequency of early colorectal cancer in inflammatory bowel disease. Gut 57:1246-1251
29. Oussaissi M, Maggiori L, Alves A et al (2011) Colorectal cancer complicating inflammatory bowel disease: a comporative study of Crohn's disease vs ulcerative colitis in 34 patients. Colorectal Dis 13:684-688

30. Olén O, Erichsen R, Sachs MC, Pedersen L, Halfvarson J, Askling J, Ekbom A, Sorensen HT, Ludvigsson JF (2020) Colorectal cancer in ulcerative colitis: a Scandinavian population-based cohort study. Lancet 395:123-131

31. Munkholm P (2003) Review article: the incidence and prevalence of colorectal cancer in inflammatory bowel disease. Aliment Pharmacol Ther 18(Suppl 2):1-5

32. Al-Sukhni W, McLeod RS, MacRae H, O'Connor B, Huang H, Cohen Z (2010) Oncologic outcome in patients with ulcerative colitis associated with dysplasia or cancer who underwenjt stapled or handsewn ileal pouch-anal anastomosis. Dis Colon Rectum 53:1495-1500

33. Jensen AB, Larsen M, Gilsum M et al (2006) Survival after colorectal cancer in patients with ulcerative colitis: a nationwide population-based Danish study. Am J gastroenbterol 101:1283-1287

34. Gyde SN, Prior P, Thompson H et al (1984) Survival of patients with colorectal cancer complicating ulcerative colitis. Gut 25:228-231

35. Kiran RP, Khoury W, Church JM, Lavery IC, Fazio VW, Remzi FH (2010) Colorectal cancer complicating inflammatory bowel disease: similarities and differences between Crohn's and ulcerative colitis based on three decades of experience. Ann Surg 252:330

36. Lavery IC, Chiulli RA, Jagelman DG et al (1982) Survival of carcinoma arising in mucosal ulcerative colitis. Ann Surg 195:508-512

37. Bye WA, Nguyen TM, Parker CE, Jairath V, East JE (2017) Strategies for detecting colon cancer in patients with inflammatory bowel disease. Cochrane Database Syst Rev 9:CD000279

38. Yager R, Hersch J, Bates D, Paroder V, Chou JF, Tang LH, Gollup MJ, Capanu M, Kelsen DP (2018) Outcomes for matched patients with metastatic colitis-associated cancers versus sporadic colorectal cancer receiving chemotherapy. J Clin Oncol 36:e15534

39. Wu X, Kiran RP, Remzi FH, Katz S, Mukewar S, Shen B (2013) Preoperative pelvic radiation increases the risk for ileal pouch failure in patients with colitis-associated colorectal cancer. J Crohn Colitis 7:e419-e426

40. Fujiwara I, Yashiro M, Kubo N, Maeda K, Hirakawa K (2008) Ulcerative colitis-associated colorectal cancer is frequently associated with the microsatellite instability pathway. Dis Colon Rectum 51:1387-1394

41. Venderbosch S, Nagtegaal ID, Maughan TS, Smith CG, Cheadle JP, Fisher D et al (2014) Mismatch repair status and BRAF mutation status in metastatic colorectal cancer patients: a pooled analysis of the CAIRO, CAIRO2, COIN, and FOCUS studies. Clin Cancer Res 20:5322-5330

42. Wang B, Li F, Guo L, Lu S, Ma J, Ma Y, Meng Y, Wasng J, Zhou X, Fu W (2020) Loss of survival advantage for deficient mismatch repair in patients with advanbced colorectal cancer may be caused by changes in prognostic value of $\mathrm{CD}(+\mathrm{T}$ cell. World J Surg Oncol 18:196-204

43. Itzkowitz SH, Present DH (2005) Consensus conference: Colorectal cancer screening and surveillance in inflammatory bowel disease. Inflamm Bowel Dis 11:314-321

44. Bernstein CN, Shanahan F, Weinstein WM (1994) Are we telling patients the truth about surveillance colonoscopy in ulcerative colitis? Lancet 343:71-74

45. Ullman T, Croog V, Harpaz N et al (2008) Progression to colorectal cancer neoplasia in ulcerative colitis: effect of 5-aminosalicylic acid. Clin Gastroenterol Hepatol 6:1225-1230 
46. Befrits R, Ljung T, Jaramillo E, Rubiuo C (2002) Low grade dysplasia in extensive, long-standing inflammatory bowel disease: a follow-up study. Dis Colon Rectum 45:615-620

47. Navaneethan U, Jegadeesan R, Gutierrez NG, Venkatesh PGK, Hammel JP, Shen B, Kiran RP (2013) Progression of low-grade dysplasia to advanced neoplasia based on the location and morphology of dysplasia in ulcerative colitis patients with extensive colitis under colonoscopic surveillance. J Crohn Colitis 7:e684-e691

48. Fumery M, Dulai PS, Gupta S, Prokop LJ, Ramamoorthy S, Sandborn WJ, Singh SW (2017) Incidence, riski factors, and outcomes of colorectal cancer in patients with ulcerative colitis with low-grade dysplasia: a systematic review and meta-analysis. Clin Gastroenterol Hepatol 15:665-674

49. Wanders LK, Dekker E, Pullens B et al (2014) Cancer risk after resection of polypoidm dysplasia in patients with longstanding ulcerative colitis: a meta-analysis. Clin Gastroenterol Hepatol 12:756-764

50. Lennard-Jones JE, Melville DM, Morson BC et al (1990) Precancer and cancer in extensive ulcerative colitis: findings among 401 patients over 22 years. Gut 31:800-806

51. Thomas T, Nair P, Dronfield NW, Mayberry JF (2005) Management of low and high-grade dysplasia in inflammatory bowel disease: the gastroenterologist'perspective and current practice in the United Kingdom. Eur J Gastroenterol Hepatol 17:1317-1324

52. Oresland T, Bemelman WA, Sampietro GM, Spinelli A et al (2015) European evidence based consensus on surgery for ulcerative colitis. J Crohn Colitis 9:4-25

53. Mutaguchi M, Naganuma M, Sugimoto S, Fukuda T, Nanki K, Mizuno S, Hosoe N, Shimoda M, Ogata H, Iwao Y, Kanai $\mathrm{T}$ (2019) Difference in the clinical characteristic and prognosis of colitis-associated cancer and sporadic neoplasia in ulcerative colitis. Dig Liver Dis 51:1257-1264

54. Kavanagh DO, Carter MC, Keegan D, Doherty G, Smith MJ, Hyland JMP, Mulcahy H, Sheahan K, O'Connell PR, O'Donoghue DP, Winter DC (2014) Management of colorectal cancer in patients with inflammatory bowel disease. Tech Coloproctol 18:23-28

55. Abdalla M, Landerholm K, Andersson P, Andersson R, Myrelid P (2017) Risk of rectal cancer after colectomy for patients with ulcerative colitis: a national cohort study. Clòin Gastroenterol Hepatol 15:1055-1060

56. Gorfine SR, Harris MT, Bub DS, Bauer JJ (2004) Restorative proctocolectomy for ulcerative colitis complicated by colorectal cancer. Dis Colon Rectum 47:1377-1385

57. Chapman JR, Larson DW, Wolff BG, Dozois EJ, Cima RR, Pemberton JH, Crownhart BS, Larson DR (2005) Ileal pouch-anal anastomosis. Does age at the time of surgery affect outcome? Arch Surg 140:534-540
58. Radice E, Nelson H, Devine RM et al (1998) Ileal pouch-anal anastomosis in patients with colorectal cancer: long-term functional and oncological outcomes. Dis Colon Rectum 41:11-17

59. Zmora O, Spector D, Dotan I, Klausner JM, Rabau M, Tulchinsky $\mathrm{H}$ (2009) Is stapled ileal pouch-anal anastomosis a safe option in ulcerative colitis patients with dysplasia or cancer? Int J Colorectal Dis 24:1181-1186

60. Merchea A, Wolff BG, Dozois EJ et al (2012) Clinical features and oncologic outcomes in patients with rectal cancer and ulcerative colitis: a single-institution experience. Dis Colon Rectum 55:881-885

61. Remzi FH, Preen M (2003) Rectal cancer and ulcerative colitis: does it change the therapeutic approach? Colorectal Dis 5:483-485

62. McCawley N, Clancy C, O’Neill BDE, Deasy J, McNamara DA, Burke JP (2016) Mucinous rectal adenocarcinoma is associated with a poorer response to neoadjuvant chemoradiotherapy: a systematic review and meta-analysis. Dis Colon Rectum 59:1200-1208

63. Das P, Johnson MW, Tekkis PP, Nicholls RJ (2007) Risk of dysplasia and adenocarcinoma following restorative proctocolectomy for ulcerative colitis. Colorectal Dis 9:15-27

64. Mark-Christensen A, Erichsen R, Brandsborg S, Rosenberg J et al (2018) Long-term risk of cancer following ileal pouch-anal anastomosis for ulcerative colitis. J Crohn Colitis 10:57-62

65. Imam MH, Eaton JE, Puckett JS, Loftus EV Jr, Mathis KL, Gossard AA, Talwalkar JA, Lindor KD (2014) Neoplasia in the ileoanal pouch following colectomy in patients with ulcerative colitis and primary sclerosing cholangitis. J Crohn Colitis 8:1294-1299

66. Kariv R, Remzi FH, Bennett AE, Kiran Y, Fazio VW, Lavery IC, Shen B (2010) Preoperative colorectal neoplasia increases risk for pouch neoplasia in patients with restorative proctocolectomy. Gastroenterology 139:806-812

67. Silva-Velazco J, Stochhi L, Wu X, Shen B, Remzi FH (2014) Twenty-year-old stapled pouches for ulceratrive colitis without evidence of rectal cancer: implications for surveillance strategy? Dis Colon Rectum 57:1275-1281

68. Selvaggi F, Pellino G, Canonico S, Sciaudone G (2014) Systematic review of cuff and pouch cancer in patients with ileal pelvic pouch for ulcerative colitis. Inflamm Bowel Dis 20:1296-1308

69. Pellino G, Kontovounisios C, Tait D, Nicholls J, Tekkis P (2017) Squamous cell carcinoma of the anal trransitional zone after ileal pouch surgery for ulcerative colitis: systematic review and treatment perpectives. Case Rep Oncol 10:112-122

Publisher's Note Springer Nature remains neutral with regard to jurisdictional claims in published maps and institutional affiliations. 